\title{
REVIEW
}

\section{A Review of the Combination of Phentermine and Topiramate Extended-Release for Weight Loss}

Kristine J. Steffen · Ronette L. Kolotkin

To view enhanced content go to www.combitherapy-open.com Received: August 8, 2012 / Published online: October 24, 2012

(C) The Author(s) 2012. This article is published with open access at Springerlink.com

\section{ABSTRACT}

The Food and Drug Administration recently approved the combination of phentermine and extended-release topiramate (PHN/TPM) for weight loss. This is one of only two weight-loss agents to arrive on the US market in the last decade. This product combines the anorexigenic agent, phentermine, which is approved for the short-term treatment of weight loss, with a carbonic anhydrase inhibitor, topiramate, which

\section{K. J. Steffen (凷}

Neuropsychiatric Research Institute, 120 8th Street South, Fargo, North Dakota, 58103, USA

University of North Dakota School of Medicine and Health Sciences, Department of Clinical Neuroscience, Grand Forks, North Dakota, USA

e-mail: ksteffen@nrifargo.com

\section{R. L. Kolotkin}

Obesity and Quality of Life Consulting, Durham, North Carolina, USA

Duke University School of Medicine, Department of Community and Family Medicine, Durham, North Carolina, USA

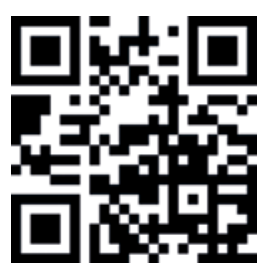

Enhanced content for this article is available on the journal web site: www.combitherapy-open.com is approved for non-weight loss indications, including seizure disorders and migraine headache. Although the combination is believed to be synergistic, no clinical trial data currently address this. The PHN/TPM combination is a once-daily formulation. Mean weight loss among participants who completed 1 year of PHN/TPM treatment in research trials, in combination with lifestyle modification, has ranged from approximately $7 \%$ (lower doses) to over $14 \%$ (higher doses), relative to approximately $2 \%$ with placebo. In addition to weight loss, PHN/TPM resulted in improved comorbidities and quality of life, although it has not been shown to improve mental/psychosocial issues. Among the common adverse events observed in clinical trials are paresthesia, dry mouth, constipation, and headache. Other noteworthy adverse events that occurred more commonly with PHN/TPM versus placebo included dysgeusia, insomnia, irritability, and alopecia. Laboratory abnormalities in serum bicarbonate and potassium were also observed in a subset of patients. Due to the teratogenic potential of topiramate, women of childbearing potential are required to have a negative pregnancy test at baseline and are instructed to take monthly pregnancy tests. As part of a riskmanagement approach, only pharmacies certified 
by the manufacturer will be allowed to dispense PHN/TPM and will be required to provide information on birth defects. Like phentermine, the combination drug will be designated as a schedule IV medication. In comparison with other agents currently on the market, the combination of PHN/TPM appears to provide significant advantages for weight loss, while improving comorbid conditions and quality of life. Monitoring for laboratory abnormalities, adverse events, and changes in psychiatric status should occur during therapy.

Keywords: Combination; Obesity; Phentermine; Phentermine/topiramate; Topiramate; Weight loss

\section{INTRODUCTION}

Obesity leads to premature death [1] and impairs quality of life [2-4]. A representative sample of US adults in 2009-2010 indicated that 35.5\% of men and $35.8 \%$ of women are obese [5]. Healthcare expenditures attributable to obesity were projected to reach $\$ 147$ billion in 2008 [6]. In 2006, per capita medical spending was $\$ 1,429$ higher for obese versus nonobese individuals [6]. Obesity is associated with several of the most common causes of mortality in the US: heart disease, stroke, certain cancers, diabetes, and renal disease [7]. One in every eight deaths is attributable to an illness directly related to obesity [8]. Despite these individual and societal burdens of obesity, treatment options remain limited.

A minority of patients is extremely successful in attaining and maintaining significant weight loss through lifestyle modification alone [9]. For the majority, however, lifestyle modification in the absence of a behavioral weight-loss program, pharmacotherapy regimen, or weightloss surgery is inadequate. Pharmacotherapy is a much needed intermediate intervention for those who are unsuccessful with lifestyle intervention alone and for whom weight-loss surgery is not indicated or desired. Currently, the pharmacotherapeutic options for obesity management are extremely limited. Although several drugs are in the obesity pipeline, the process for getting such drugs to market has recently proven difficult.

\section{MATERIALS AND METHODS}

Studies were found using PubMed. No limits on dates were set. Major keywords included phentermine and topiramate, phentermine, topiramate, pharmacotherapy for weight loss, lorcaserin, orlistat, and others.

\section{INDICATIONS AND EFFICACY BENCHMARKS FOR PHARMACOTHERAPY}

Pharmacotherapy for obesity is indicated for patients with a body mass index (BMI) $\geq 30 \mathrm{~kg} / \mathrm{m}^{2}$ or $27-29.9 \mathrm{~kg} / \mathrm{m}^{2}$ with a comorbid condition that increases cardiometabolic risk [10]. Pharmacotherapy is indicated in conjunction with supportive lifestyle modification counseling [11], and should be used with a reduced calorie diet and exercise regimen. Current indications for bariatric surgery include a BMI of $\geq 40 \mathrm{~kg} / \mathrm{m}^{2}$ or $\geq 35 \mathrm{~kg} / \mathrm{m}^{2}$ with significant obesity-related disorders [12]. Therefore, a substantial percentage of the population who are overweight/obese but do not meet criteria for surgery may benefit from a pharmacological intervention.

According to the US Food and Drug Administration (FDA), a weight-loss medication is deemed effective if it demonstrates one of the following after 1 year of treatment: (1) "The difference in mean weight loss between the active-product and placebo-treated groups is 
at least $5 \%$ and the difference is statistically significant," or (2) "The proportion of subjects who lose $\geq 5 \%$ of baseline body weight in the active-product group is at least $35 \%$, is approximately double the proportion in the placebo-treated group, and the difference between groups is statistically significant." In addition, the FDA expects improvements in blood pressure, lipids, glycemia, or other comorbidities that are commensurate with the degree of weight lost [13].

\section{A PERILOUS PAST FOR WEIGHT- LOSS PHARMACOTHERAPY}

A historical look at the fate of some of the most commonly used prescription and herbal products for weight loss over the last three decades reveals multiple issues, which may have contributed to the FDA's hesitancy in approving new medications. Dinitrophenol was withdrawn for risk of neuropathy and cataracts, aminorex was withdrawn due to pulmonary hypertension, and amphetamine use was discouraged due to risk of dependency and cardiac adverse events [14]. In 2004, the FDA mandated the removal of ephedrine-containing products due to cardiovascular concerns. Phenylpropanolamine, a sympathomimetic amine widely used as an appetite suppressant, was withdrawn in 2000 after being associated with intracranial hemorrhage [15].

Perhaps the most memorable pitfall in obesity pharmacotherapy involved fenfluraminephentermine (fen-phen) in 1997. Although this combination was efficacious and widely prescribed, fenfluramine was withdrawn following FDA concerns about cardiac valve damage $[16,17]$.

Sibutramine was withdrawn in 2010 after results of the Sibutramine Cardiovascular Outcomes Trial (SCOUT) became available [18].
The SCOUT trial was a large, placebo-controlled, multicenter trial sponsored by the drug's manufacturer to determine whether the drug could reduce cardiovascular mortality in a high-risk sample. Contrary to the study hypothesis, patients receiving sibutramine had a significantly higher rate of cardiovascular events versus placebo with overall incidences of $11.4 \%$ versus $10 \%$, respectively. Although the sibutramine package labeling warned against treating patients at high cardiac risk, the FDA issued new warnings based upon these data, which ultimately led to the drug's withdrawal.

Although never available in the US market, cannabinoid 1 receptor (CB1) antagonists, such as rimonabant, were in late-stage development by several pharmaceutical companies before being aborted due to the increased risk of depression/suicide. Rimonabant was also removed from the European market.

Other weight-loss medications and drug combinations are in the development process, including bupropion/naltrexone, bupropion/zonisamide, and tesofensine. The FDA approved Qsymia $^{\mathrm{TM}}$ (Vivus, Inc., Mountain View, California, USA), a combination of phentermine and topiramate extended-release (PHN/TPM), most recently.

\section{CURRENTLY AVAILABLE PHARMACOTHERAPY OPTIONS}

In addition to phentermine, which is approved for the short-term treatment ( 3 months) of obesity, two additional agents are approved for longer term use. Orlistat is a lipoprotein lipase inhibitor available in prescription (120 mg) and over-the-counter formulations (60 mg), which works by inhibiting the breakdown and absorption of dietary fat. The pharmacological activity of orlistat is localized to the gastrointestinal tract, with less than $2 \%$ of the 
drug being absorbed into systemic circulation [19]. This results in a toxicity profile consisting of gastrointestinal adverse effects, but relatively few serious side effects. However, the efficacy of orlistat is modest. A meta-analysis of orlistat trials of at least 12 months in duration showed a mean weight loss of $2.89 \mathrm{~kg}$ (95\% confidence intervals [CI]: $2.27-3.51 \mathrm{~kg}$ ) [20].

Lorcaserin is a serotonin $2 \mathrm{C}$ agonist that was recently approved by the FDA for weight loss at a dose of $10 \mathrm{mg}$ twice daily. In three large, controlled trials lasting 52-104 weeks, including approximately 8,000 patients, placebo-subtracted weight loss was 3.0-3.7\%, when combined with reduced calorie diet and exercise [21]. The most common adverse effects of lorcaserin in patients without diabetes included headache, dizziness, fatigue, nausea, dry mouth, and constipation. In diabetic patients, the most common side effects included hypoglycemia, headache, back pain, cough, and fatigue [21].

\section{PHENTERMINE/EXTENDED-RELEASE TOPIRAMATE}

In July 2010, an FDA advisory committee rejected PHN/TPM, with a vote of 10 to 6 , due to concerns about increased heart rate, teratogenicity, and suicidality. In October 2010, the FDA requested additional data from Vivus, its manufacturer, to address these concerns. In February 2012, an FDA Scientific Advisory Committee recommended approval of PHN/TPM with some changes from the original submission. In July of 2012, PHN/TPM (formerly Qnexa ${ }^{\circledR}$ [Vivus, Inc.]) was approved as a schedule IV drug under the brand name, Qsymia ${ }^{\mathrm{TM}}$.

\section{FORMULATION AND DOSAGES}

PHN/TPM is a combination of an immediaterelease formulation of the anorexigenic agent, phentermine, and an extended-release formulation of the anticonvulsant medication, topiramate. Phentermine, with a history of use spanning 52 years, is currently the most widely prescribed drug for weight loss in the US with over 6.5 million prescriptions written in 2011 [22]. Topiramate has a 15-year history of use. The drug combination is formulated to produce peak exposure to phentermine in the morning and peak concentrations of topiramate in the evening [22].

The drug was approved in four dosage strengths of PHN/TPM: 3.75/23 mg, 7.5/46 mg, $11.25 / 69 \mathrm{mg}$, and $15 / 92 \mathrm{mg}$. The scientific rationale for the specific doses included in the combination is not clear, for example, $92 \mathrm{mg}$ topiramate instead of the commercially available $100 \mathrm{mg}$ dosage form of topiramate. The doses of topiramate used for weight loss are somewhat lower than for the other indications of the drug. The recommended migraine headache prophylaxis dose is $100 \mathrm{mg} /$ day given in two divided doses [23]. The dose for partial-onset seizure and primary generalized tonic-clonic seizure is up to a maximum of $400 \mathrm{mg} /$ day given in two divided doses, and similar doses are used for adjunctive therapy in these seizure disorders [24]. Topiramate doses up to $1,600 \mathrm{mg}$ /day have been studied in epilepsy [23].

For weight loss, the recommended dosing is $3.75 / 23 \mathrm{mg}$ once daily (in the morning) for 14 days with an increase to $7.5 / 46 \mathrm{mg}$ thereafter [25]. If at least $3 \%$ of baseline body weight has not been lost after 12 weeks, the dose may be escalated or discontinued. If the dose is escalated, it should be done by prescribing the $11.25 / 69 \mathrm{mg}$ dose for 14 days followed by increasing to the $15 / 92 \mathrm{mg}$ dose. If after an additional 12 weeks on PHN/TPM 15/92 mg the patient has not experienced 5\% weight loss, the drug should be discontinued [25]. Doses of $3.75 / 23 \mathrm{mg}$ and $11.25 / 69 \mathrm{mg}$ should be used for 
titration purposes [25]. When discontinued, the drug should be reduced gradually by taking a dose every other day for at least a week before stopping treatment to prevent the precipitation of seizures [25]. In patients with moderate (creatine clearance $\geq 30$ to $<50 \mathrm{~mL} / \mathrm{min}$ ) and severe $(<30 \mathrm{~mL} / \mathrm{min})$ renal dysfunction, the maximum dose should not exceed 7.5/46 mg.

\section{MECHANISM OF ACTION AND EFFICACY OF INDIVIDUAL AGENTS}

\section{Topiramate}

It has been suggested that topiramate and phentermine may have synergistic effects toward weight loss [26], although this theory has not been tested in clinical trials. Until the combination of PHN/TPM is compared against each of the agents individually, claims of synergy cannot be addressed. Topiramate is currently FDA-approved for the treatment of seizure disorders and prophylaxis of migraine headaches [23]. The mechanism of action that contributes to weight loss is currently unclear. The pharmacology of topiramate is complex. It is known to block neuronal voltage-dependent sodium channels, antagonize 2-amino-3(5-methyl-3-oxo-1,2-oxazol-4-yl)propanoic acid/ kainite glutamate receptors, enhance gammaaminobutyric acid activity, and weakly inhibit carbonic anhydrase [23].

Topiramate has been associated with weight loss in many treatment trials, including epilepsy [24], migraine headache [27, 28], bulimia nervosa [29, 30], binge-eating disorder [31, 32], antipsychotic-associated weight gain [33, 34], and obesity [35]. A recent meta-analysis [35] evaluated weight loss associated with topiramate across 10 randomized, controlled trials (RCTs) in overweight or obese patients, with or without comorbid conditions. Overall, patients lost an average of $5.34 \mathrm{~kg}$ (95\% CI -6.12 to $-4.56 \mathrm{~kg})$ beyond the loss observed with placebo [35]. This meta-analysis also showed that trials with longer treatment durations ( $>28$ weeks duration) demonstrated greater weight loss $(6.58 \mathrm{~kg}$; [95\% CI -7.48 to $-5.68 \mathrm{~kg}]$ ) and that doses over $96 \mathrm{mg} /$ day were associated with higher discontinuation rates in trials.

A recent 3-month study of 40 patients treated with topiramate $100 \mathrm{mg} /$ day for migraine prophylaxis found no change in resting metabolic rate [36]. There were, however, statistically significant reductions in mean BMI, body fat ratio, and abdominal skin-fold measurements. The findings of this study led the authors to conclude that the anorexigenic activity of topiramate may occur through hypothalamic activity. It has been suggested that topiramate may also lead to weight loss through increased satiety due to decreased gastrointestinal motility, increased taste aversion, increased energy expenditure, and decreased caloric intake [22]. The propensity of topiramate to contribute to neuropsychiatric and cognitive events at higher dosages has hindered its development as a monotherapy for weight loss [37].

\section{PHENTERMINE}

Phentermine was approved by the FDA in 1959 . Appetite reduction associated with phentermine is thought to be centrally mediated, including hypothalamic stimulation that results in norepinephrine release [23]. Phentermine is indicated for short-term use for weight reduction, in combination with a reduced calorie diet and exercise [23]. The utility of phentermine when used short-term according to its labeling is questionable.

Off-label use of phentermine has been examined in clinical trials of longer duration. A meta-analysis [20] evaluated the results 
of six placebo-controlled RCTs. These trials ranged from 2-24 weeks and involved dosages of 15-30 mg/day. Lifestyle intervention was included in over $80 \%$ of patients. The average weight loss in these trials was $3.6 \mathrm{~kg}$ (95\% CI 0.6-6.0 kg) above placebo.

Phentermine is generally well-tolerated. Common side effects are characteristic of sympathomimetic amines, including dry mouth, headache, insomnia, nervousness, irritability, and constipation. More serious side effects include palpitations, tachycardia, and hypertension [38]. Phentermine should be avoided in patients with hyperthyroidism, glaucoma, agitated states, advanced arteriosclerosis, symptomatic cardiovascular disease, moderate-severe hypertension, a history of substance abuse, or those who would have a drug interaction (e.g., monoamine oxidase inhibitors).

\section{CLINICAL TRIALS INVOLVING PHN/TPM}

Three large RCTs address the efficacy of PHN/TPM for weight loss. A fourth trial has been completed but not yet published (EQUATE). These trials provide efficacy and tolerability information regarding the effect of this drug combination on comorbid conditions. All trials were funded by Vivus, the manufacturer of the PHN/TPM combination. The published trials include: CONQUER [37], EQUIP [39], and SEQUEL [40]. The results of each of these trials will be discussed in detail and a summary of each is presented in Table $1[37,39,40]$.

The EQUIP study [39] was a 56-week, three-arm, double-blind, parallel-group study conducted at 91 centers across the US. The study included a blinded 4 -week titration period and subsequent 52-week treatment period. Patients 18-70 years of age were included who had a BMI of $\geq 35 \mathrm{~kg} / \mathrm{m}^{2}$. Patients were relatively free of comorbid conditions. Participants were randomized in a 2:1:2 ratio to placebo ( $n=514)$, PHN/TPM 3.75/23 mg $(n=241)$, and PHN/TPM 15/92 mg $(n=512)$. Participants were provided with "standardized lifestyle counseling" based upon the Lifestyle, Exercise, Attitudes, Relationships, and Nutrition (LEARN) manual [41] and were instructed to follow a 500 kcal dietary reduction along with increased water intake with increased physical activity. Participants were mostly women (83\%) and the mean total BMI was $42 \mathrm{~kg} / \mathrm{m}^{2}$.

The CONQUER study [37] was a 56-week, randomized, double-blind RCT conducted at 93 centers across the US. Participants 18-70 years of age were enrolled with a BMI $\geq 27-\leq 45 \mathrm{~kg} / \mathrm{m}^{2}$, with two or more comorbid conditions (hypertension, hyperlipidemia, diabetes, impaired glucose tolerance, or high waist circumference). The majority of patients in this trial were women (70\%), and the mean BMI was $36.6 \mathrm{~kg} / \mathrm{m}^{2}$. Comorbidity rates were hypertension (52\%), hypertriglyceridemia (36\%), impaired glucose tolerance or impaired fasting glucose (68\%), and type 2 diabetes (16\%). Patients were randomized in a 2:1:2 ratio to either daily placebo, PHN/TPM 7.5/46 mg, or PHN/TPM 15/92 mg. As with EQUIP, participants received lifestyle counseling, and dietary and fitness instructions.

The SEQUEL study [40] assessed the efficacy and safety of PHN/TPM for longer-term use in overweight/obese individuals with existing cardiometabolic disease. This was a 52-week, placebo-controlled, double-blind, extension study following CONQUER. Participants who completed and complied with the CONQUER trial were eligible for SEQUEL. Patients continued the product to which they were originally randomized, in conjunction with lifestyle modification. Interestingly, more participants met criteria for type 2 diabetes mellitus at baseline in 
Table 1 Overview of major PHN/TPM studies

\begin{tabular}{|c|c|c|c|c|}
\hline $\begin{array}{l}\text { Study name, } \\
\text { primary author, } \\
\text { year, study sponsor }\end{array}$ & $\begin{array}{l}\text { Study duration, } \\
\text { study design, } \\
\text { intervention(s) }\end{array}$ & $\begin{array}{l}\text { Participants: } \\
N \text {, characteristics }\end{array}$ & $\begin{array}{l}\text { Efficacy: } \\
\text { \% weight loss }\end{array}$ & Attrition and reasons \\
\hline EQUIP [39] & 56 weeks & $\begin{array}{l}\text { plc: } n=514 \\
3.75 / 23: n=241\end{array}$ & $\begin{array}{l}\text { ITT analysis: } \\
\text { plc: } 1.6 \%\end{array}$ & $\begin{array}{l}\text { Completion rates: } \\
\text { total: } 53.7 \%\end{array}$ \\
\hline Allison et al., 2011 & $\mathrm{DB}, \mathrm{RCT}$ & $15 / 92: n=512$ & $\begin{array}{l}3.75 / 23: 5.1 \% \\
15 / 92: 10.9 \%\end{array}$ & $\begin{array}{l}\text { plc: } 46.9 \% \\
3.75 / 23: 57.3 \%\end{array}$ \\
\hline Vivus, Inc. & $\begin{array}{l}\text { Energy deficit, LEARN } \\
\text { manual + one of } \\
\text { three groups }\end{array}$ & $\begin{array}{l}M \& F \\
\text { Age } 18-70 \text { years } \\
B M I \geq 35 \mathrm{~kg} / \mathrm{m}^{2}\end{array}$ & $\begin{array}{l}\text { Completer analysis: } \\
\text { plc: } 2.1 \% \\
3.75 / 23: 6.7 \% \\
15 / 92: 14.4 \%\end{array}$ & $\begin{array}{l}\text { Most common reasons: } \\
\text { - lost to follow-up } \\
\text { - withdrawal of consent } \\
\text { - adverse events }\end{array}$ \\
\hline CONQUER [37] & 56 weeks & $\begin{array}{l}\text { plc: } n=994 \\
7.5 / 46: n=498\end{array}$ & $\begin{array}{l}\text { ITT analysis: } \\
\text { plc: } 1.2 \%\end{array}$ & $\begin{array}{l}\text { Completion rates: } \\
\text { total: } 69.3 \%\end{array}$ \\
\hline Gadde et al., 2011 & $\mathrm{DB}, \mathrm{RCT}$ & $15 / 92: n=995$ & $\begin{array}{l}7.5 / 46: 7.8 \% \\
15 / 92: 9.8 \%\end{array}$ & $\begin{array}{l}\text { plc: } 62 \% \\
7.5 / 46: 75.1 \% \\
15 / 92: 73.7 \%\end{array}$ \\
\hline Vivus, Inc. & $\begin{array}{l}\text { Energy deficit, LEARN } \\
\text { manual + one of } \\
\text { three groups }\end{array}$ & $\begin{array}{l}\mathrm{BMI} \geq 27 \text { and } \\
\leq 45 \mathrm{~kg} / \mathrm{m}^{2}+\text { two } \\
\text { or more } \\
\text { comorbidities }\end{array}$ & $\begin{array}{l}\text { Completer analysis: } \\
\text { plc: } 1.6 \% \\
7.5 / 46: 9.6 \% \\
15 / 92: 12.4 \%\end{array}$ & \\
\hline SEQUEL [40] & $\begin{array}{l}\text { 52-week extension } \\
\text { after } 56 \text {-week }\end{array}$ & $\frac{n \text { (\% of CONQUER }}{\text { patients) }}$ & $\begin{array}{l}\text { ITT-LOCF: } \\
\text { plc: } 1.8 \% \\
7.5 / 46: 9.3 \%\end{array}$ & $\begin{array}{l}\text { Completion rates } \\
\text { (weeks } 56-108 \text { ): } \\
\text { plc: } 86.3 \%\end{array}$ \\
\hline Garvey et al., 2012 & CONQUER study & $\begin{array}{l}\text { plc: } 227(69.4 \%) \\
7.5 / 46: 153(79.4 \%) \\
15 / 92: 295(85.5 \%)\end{array}$ & 15/92: $10.5 \%$ & $\begin{array}{l}7.5 / 46: 82.5 \% \\
15 / 92: 83.1 \%\end{array}$ \\
\hline Vivus, Inc. & $\begin{array}{l}\text { DB, PC } \\
\text { Lifestyle modification }+ \\
\text { continuation in one of } \\
\text { three groups }\end{array}$ & $\mathrm{BMI} \geq 22 \mathrm{~kg} / \mathrm{m}^{2}$ & $\begin{array}{l}\text { Completer analysis: } \\
\text { plc: } 2.2 \% \\
7.5 / 46: 9.3 \% \\
15 / 92: 10.7 \%\end{array}$ & $\begin{array}{l}\text { Most common reasons } \\
\text { - lost to follow-up } \\
\text { - withdrew consent } \\
\text { - adverse event }\end{array}$ \\
\hline
\end{tabular}

3.75/23 phentermine $3.75 \mathrm{mg}+$ topiramate $23 \mathrm{mg}$ extended-release capsules, $15 / 92$ phentermine $15 \mathrm{mg}+$ topiramate $92 \mathrm{mg}$ extended-release capsules, $7.5 / 46$ phentermine $7.5 \mathrm{mg}$ + topiramate $46 \mathrm{mg}$ extended-release capsule, $B M I$ body mass index, $D B$ double-blind, $F$ female, ITT intention to treat, LEARN Lifestyle, Exercise, Attitudes, Relationships, and Nutrition, $L O C F$ last observation carried forward, $M$ male, $P C$ placebo-controlled, $P H N / T P M$ phentermine and extended-release topiramate, plc placebo, $R C T$ randomized, controlled trial 
the SEQUEL extension study compared with the CONQUER cohort (21.5\% vs. $15.8 \%$ ). Percentage rates of participation were as follows: $15 / 92 \mathrm{mg}$ (85.5\%), 7.5/46 mg (79.4\%), placebo (69.4\%).

\section{EFFICACY FOR WEIGHT LOSS}

In the EQUIP trial, weight loss was highest for patients in the 15/92 $\mathrm{mg}$ PHN/TPM group, and both drug groups lost significantly more weight than placebo in each analysis. Study completers lost $14.4 \%$ of baseline weight on PHN/TPM 15/92 mg, 6.7\% on PHN/TPM 3.75/23 mg, and $2.1 \%$ on placebo. Higher percentages of patients lost at least $5 \%, 10 \%$, and $15 \%$ of baseline weight on active medication versus placebo. Weight loss $\geq 10 \%$ was achieved by $67.7 \%$ of participants with PHN/TPM 15/92 mg, 27.7\% with PHN/TPM $3.75 / 23 \mathrm{mg}$, and $13.0 \%$ with placebo.

The CONQUER trial showed significantly greater weight reductions for both drug groups versus placebo. The completer analysis showed reductions of $-9.9 \mathrm{~kg}$ (least squares mean $-9.6 \%$ ), $-12.9 \mathrm{~kg}(-12.4 \%)$, and $-1.8 \mathrm{~kg}(-1.6 \%)$ with PHN/TPM 7.5/46 mg, 15/92 mg, and placebo, respectively. Significantly higher percentages of participants lost $\geq 10 \%$ of baseline weight in the PHN/TPM groups. This threshold was reached by $37 \%$ in the PHN/TPM 7.5/46 mg group, $48 \%$ in the PHN/TPM 15/92 mg group, and 7\% in the placebo group in ITT analyses.

Weight-loss efficacy in SEQUEL was greater in both medication groups versus placebo. Least squares mean percentage change in weight from baseline to week 108 in the intent-to-treat (ITT) Last Observation Carried Forward (LOCF) analysis was significantly greater in the PHN/TPM groups versus placebo: $-9.3 \%$ (PHN/TPM 7.5/46 mg), $-10.5 \%$ (PHN/TPM 15/92 mg), and-1.8\% (placebo). A completer analysis revealed similar results. Significantly more patients in both drug groups achieved losses of 5\%,10\%, and 15\% versus placebo. More patients in the $15 / 92 \mathrm{mg}$ dose group lost $20 \%$ or more of baseline body weight versus those on placebo. In SEQUEL, the PHN/TPM 15/92 mg dose was found to be superior to the 7.5/46 $\mathrm{mg}$ dose and placebo for weight loss in participants with the highest BMIs (baseline BMI 40 and $45 \mathrm{~kg} / \mathrm{m}^{2}$ ).

Weight loss observed in trials of PHN/TPM appears to be greater than weight loss reported in lorcaserin trials and in some of the trials of bupropion/naltrexone. In three large (approximately 8,000 patients) lorcaserin RCTs of 52-104 weeks duration, weight loss was $3.0-3.7 \%$ versus placebo when combined with reduced calorie diet and exercise [21]. Data from the first year of treatment in the large Behavioral Modification and Lorcaserin Second Study for Obesity Management (BLOSSOM) and Behavioral Modification and Lorcaserin for Overweight and Obesity Management (BLOOM) trials of lorcaserin showed a 5.8\% weight loss [42]. In four large 56-week bupropion/ naltrexone trials consisting of approximately 4,500 patients, weight loss ranged from approximately 5.0-9.3\% [43].

\section{EFFICACY FOR WEIGHT-RELATED COMORBID CONDITIONS}

In EQUIP, comorbidities improved significantly with 15/92 mg PHN/TPM versus placebo for waist circumference, systolic blood pressure (SBP), diastolic blood pressure (DBP), glucose, triglycerides, total cholesterol/high-density lipoprotein (HDL) ratio, total cholesterol, lowdensity lipoprotein (LDL) cholesterol, and HDL cholesterol. Improvements in the PHN/TPM $3.75 / 23 \mathrm{mg}$ group did not always reach statistical significance when compared against placebo.

Comorbidities in CONQUER were also generally improved in PHN/TPM versus placebo. Significant improvements were observed for 
waist circumference, blood pressure, lipids, glycemia, C-reactive protein, and adiponectin. Among patients with hypertension, those on active PHN/TPM had a greater reduction in SBP versus placebo, and patients on PHN/TPM discontinued more antihypertensive medications versus placebo. A complication in interpretation of the comorbidity data from CONQUER is that patients' comorbidities were managed according to the "standards of care" and concomitant medications could be adjusted accordingly. This makes it difficult to determine whether the PHN/TPM combination had an independent effect, or even a weight-loss mediated effect, on comorbid conditions beyond the improved monitoring and management that was provided as part of the study. The longer-term SEQUEL study found continued reduction in many comorbid conditions. Improvement in comorbidities can be reviewed in Table $2[37,39,40]$.

\section{ADVERSE EVENTS}

When PHN/TPM data were analyzed and presented to the FDA in aggregate, the most frequently reported treatment emergent adverse events included paresthesia (17\%), dry mouth (16.6\%), constipation (15.1\%), upper respiratory tract infection (13.5\%), nasopharyngitis (10\%), and headache (9.8\%) [22]. Additional doserelated adverse effects that were more common in PHN/TPM versus placebo included dysgeusia, insomnia, irritability, and alopecia [22]. Additional information on study-specific adverse events may be found in Table 2 .

\section{LABORATORY ABNORMALITIES}

It is thought that the inhibition in carbonic anhydrase that occurs with topiramate contributes to changes in bicarbonate, potassium, and risk of nephrolithiasis. When looking at laboratory results overall, there were no differences between the medication and placebo groups regarding the incidence of serious laboratory-related adverse events or drug discontinuations due to laboratory adverse events [22]. There were, however, some notable laboratory findings reported in the major trials. All cases of hypokalemia associated with a potassium value $<3 \mathrm{mmol} / \mathrm{L}$ plus a reduction of $>0.5 \mathrm{mmol} / \mathrm{L}$ from baseline reportedly occurred in patients taking non-potassium-sparing diuretics [22]. More information on laboratory abnormalities that occurred during clinical trials can be found in Table 2 .

\section{PSYCHIATRIC AND NEUROCOGNITIVE ADVERSE EVENTS}

In EQUIP, psychiatric side effects were assessed with the Patient Health Questionnaire-9 (PHQ-9) [44] and the Columbia Suicide Severity Rating Scale (C-SSRS) [45]. Mean PHQ-9 scores indicated improvements in depressive symptoms over time in all treatment groups, with no between group differences observed. No increases in suicidal ideation or behavior were identified on the C-SSRS for any participants. It should be noted that participants had minimal depressive symptoms at baseline (mean PHQ-9 = 2.8) due to exclusionary criteria (PHQ-9 >10). Data presented in study appendices reflect that there may be a small number of patients whose psychiatric function worsens while on the drug. Psychiatric and neurocognitive effects have not been specifically and thoroughly assessed in patients with clinical depression or other significant mental health disorders. Therefore, clinicians should monitor for any potential worsening of these conditions if PHN/TPM is started. 


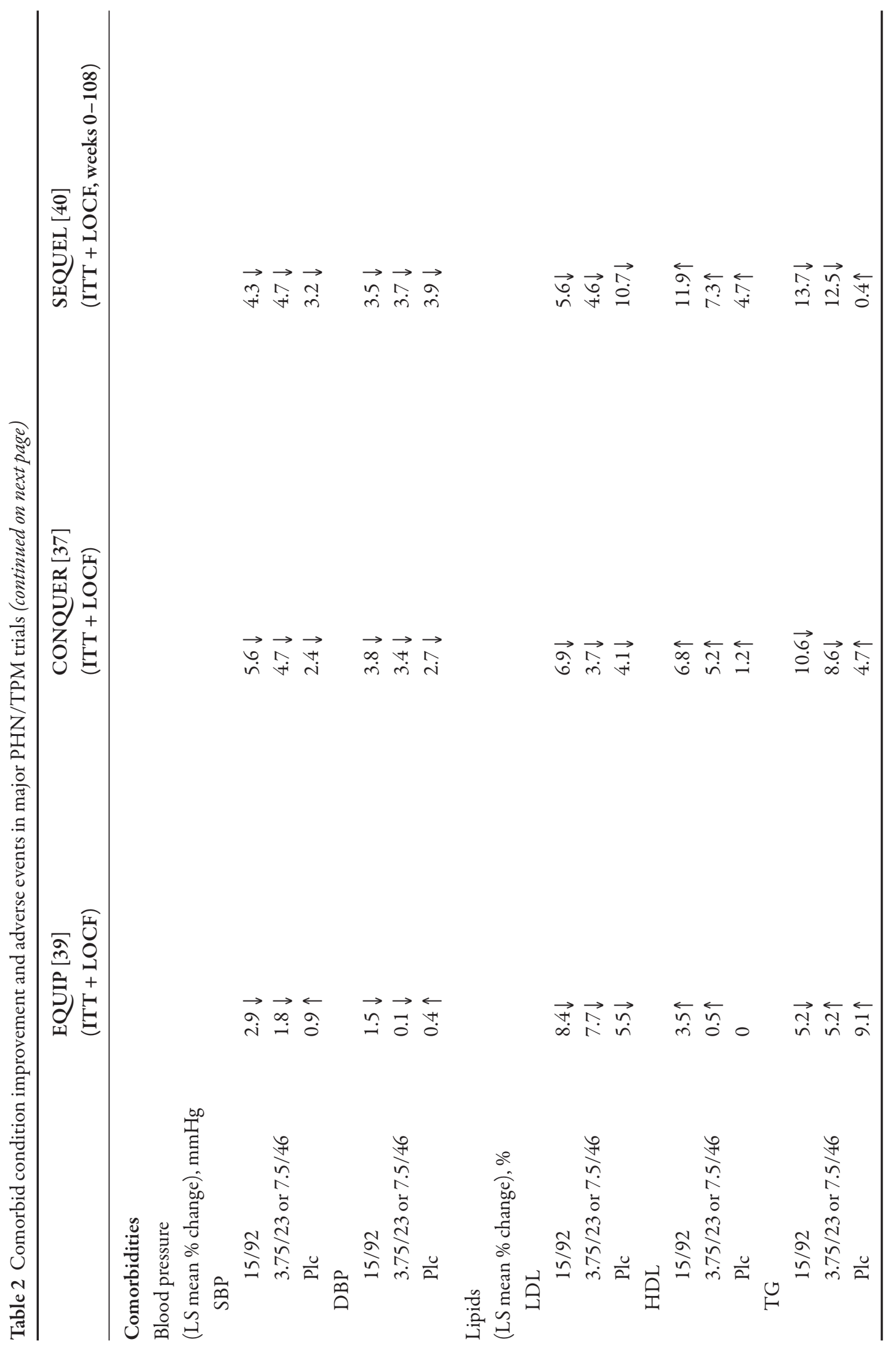




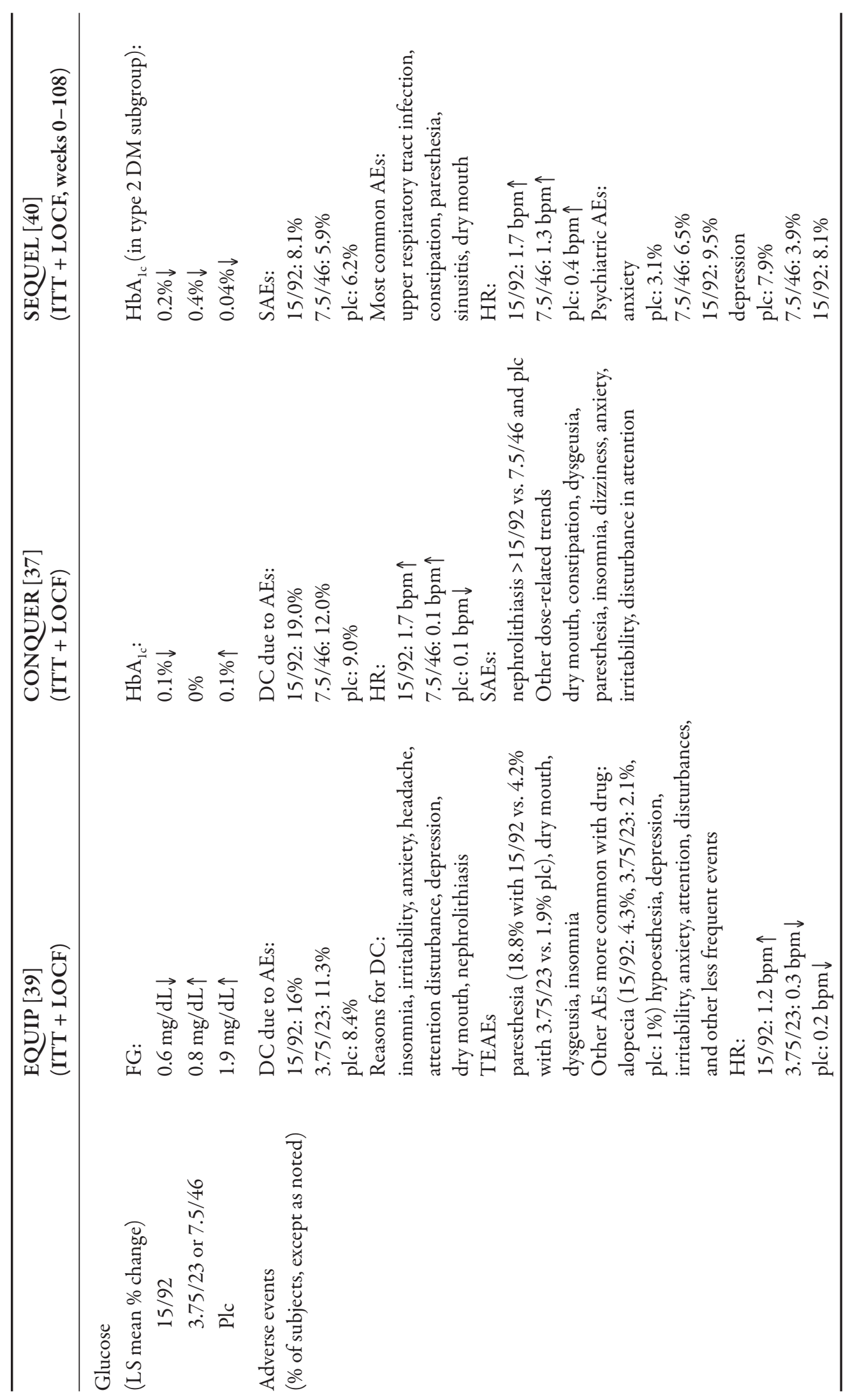




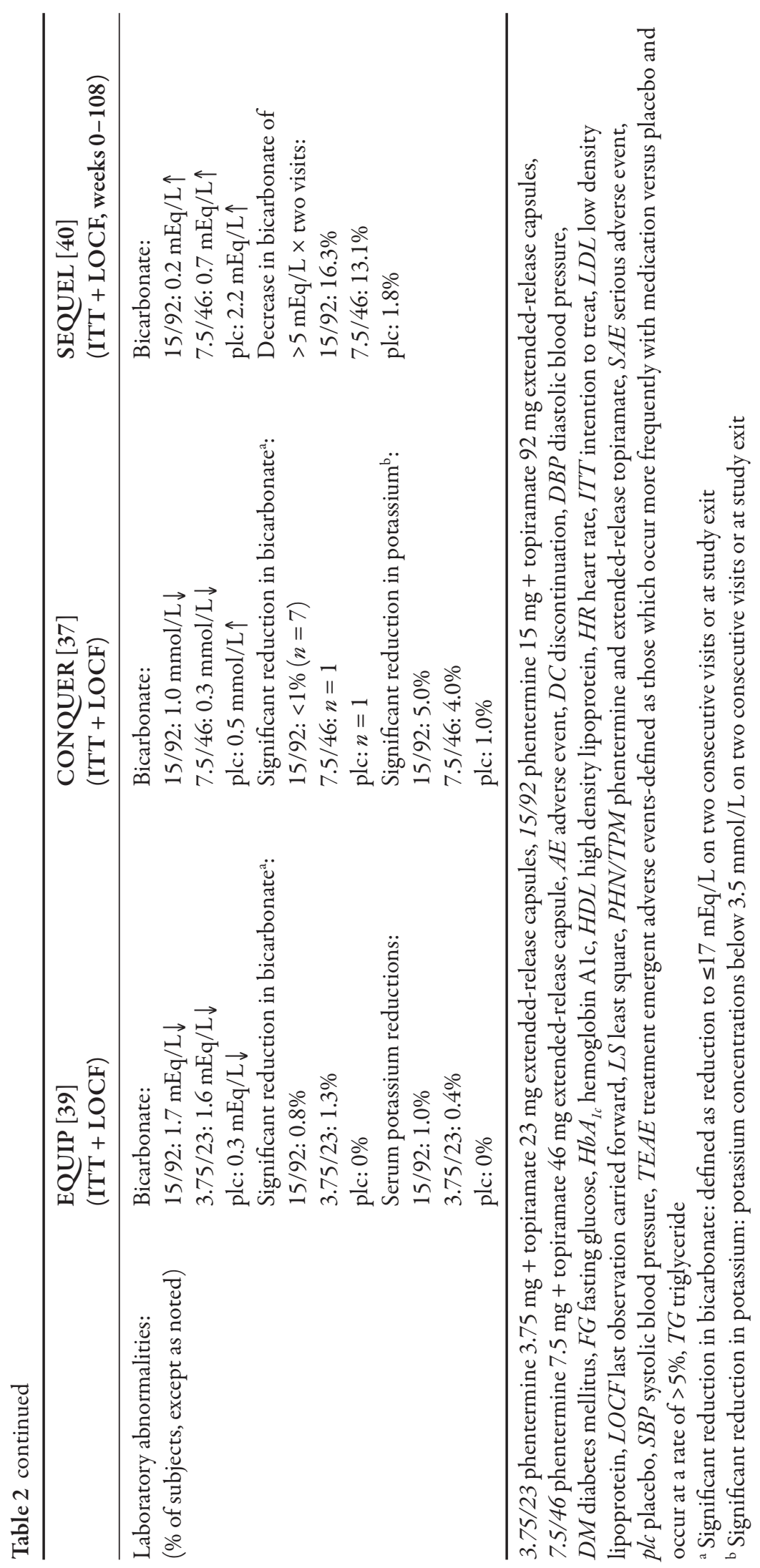


In CONQUER, no increase in suicidality was observed with drug versus placebo. Adverse event rates due to depression in the safety sample were similar in all three treatment groups (3-4\%). Anxiety and irritability were significantly more common in the PHN/TPM $15 / 92 \mathrm{mg}$ group versus placebo ( $4 \%$ vs. $2 \%$ for anxiety; $3 \%$ vs. $<1 \%$ for irritability). Generally, psychiatric adverse events occurred early in treatment (median 29 days in the PHN/TPM 15/92 mg group) and lasted 29 days (median) in the PHN/TPM 15/92 mg group. Disturbance in attention was observed in $4 \%$ of those in the PHN/TPM 15/92 mg group, 2\% in the PHN/TPM $7.5 / 46 \mathrm{mg}$ group, and $<1 \%$ in the placebo group, differences that were significant for both drug groups versus placebo. These cognitive side effects emerged to a median of 23-25 days into treatment and lasted a median of 51 days in the PHN/TPM 7.5/46 mg group and 36 days in the PHN/TPM 15/92 mg group. In all cases, cognitive disturbances resolved after drug discontinuation.

In SEQUEL, there was no apparent increase in serious suicidal ideation or suicidal behavior as assessed during the 108 weeks of observation. Depression-related adverse events were comparable between groups. Anxiety-related adverse events correlated with higher doses. Rates of anxiety were found to be $3.1 \%, 6.5 \%$, and $9.5 \%$ for placebo, PHN/TPM 7.5/46 mg, and PHN/TPM 15/92 mg, respectively. No serious anxiety-related events occurred but did lead to discontinuation in one PHN/TPM 15/92 mg patient and severe symptoms in two additional patients in the higher-dose group.

\section{PREGNANCY OUTCOMES AND POTENTIAL TERATOGENICITY}

One of the FDA Advisory Panel's major concerns with the approval of PHN/TPM involved the teratogenic potential of the drug. Topiramate is currently marketed in Pregnancy Category D. In some cases, topiramate may be continued during pregnancy when the risk of seizures in a woman with epilepsy or severe migraines outweighs the potential for fetal malformation [22]. In the case of PHN/TPM, the plan is to have a contraindication for pregnant women and immediately discontinue the drug if a woman becomes pregnant during treatment.

The teratogenic potential of PHN/TPM continues to be investigated. A large, observational retrospective study (Fetal Outcome Retrospective TopiRamate ExpoSure Study [FORTRESS]) is underway to quantify the fetal risk associated with topiramate [22]. Other sources of data concerning fetal risk with topiramate are being evaluated. To date, it appears that during the first trimester of pregnancy, topiramate has no overall effect on the prevalence of major congenital malformations, but may increase the prevalence of oral clefts by two- to fivefold. Data are currently too limited to conclusively determine the true teratogenic potential of topiramate.

Fifteen pregnancies occurred in women randomized to PHN/TPM during EQUIP. Of these, six resulted in abortion (three spontaneous, three elective), and nine resulted in healthy live births with no evidence of congenital malformation. Two pregnancies occurred in the SEQUEL study, one in the placebo group and one in the PHN/ TPM 15/92 mg group. The pregnancy in the drug group was carried to term with no evident teratogenic effects.

An additional consideration is that topiramate may interfere with the pharmacokinetics of hormonal contraceptives. Estrogen and progestin levels are reduced by topiramate, particularly at doses of $>200 \mathrm{mg} /$ day [23]. The dosage of topiramate in the combination of PHN/TPM $15 / 92 \mathrm{mg}$ was found to reduce the exposure of a single dose of ethinyl estradiol $35 \mu \mathrm{g}$ by $16 \%$ and 
increase the exposure of norethindrone $1 \mathrm{mg}$ by $22 \%$ [25]. The manufacturer states that these changes are unlikely to affect contraceptive effectiveness, although irregular bleeding may occur [25]. Nevertheless, the patient brochure on PHN/TPM recommends that oral contraceptives be used in combination with barrier methods of contraception. It is recommended by the manufacturer that women of childbearing potential produce a negative pregnancy test at baseline and monthly thereafter during therapy.

This drug will be dispensed only through pharmacies certified by the manufacturer. This requirement is part of a Risk Evaluation and Mitigation Strategy (REMS) to help prevent birth defects. To become certified, pharmacies must agree to dispense a patient medication guide and a brochure with each PHN/TPM prescription that specifically warns patients about birth defects with PHN/TPM, and pharmacies must agree to educate pharmacy personnel accordingly.

\section{QUALITY OF LIFE}

In the CONQUER trial, both health-related quality of life and weight-related quality of life were assessed; for EQUIP, only weightrelated quality of life was assessed. The Medical Outcomes Study Short Form-36 (SF-36) [46] was used to assess health-related quality of life, and the Impact of Weight on Quality of Life-Lite (IWQOL-Lite) was used to assess weight-related quality of life [47].

Participants receiving PHN/TPM 7.5/46 mg and $15 / 92 \mathrm{mg}$ in both EQUIP and CONQUER trials experienced significant improvements versus placebo $(P<0.05)$ on IWQOL-Lite total score and all subscales (physical function, selfesteem, sexual life, public distress, and work). Significant differences were observed for participants on PHN/TPM 3.75/23 mg only on physical function [48]. SF-36 results (CONQUER) indicated significant improvements for both PHN/TPM groups versus placebo $(P<0.05)$ on physical functioning, physical role, bodily pain, general health, vitality, and Physical Component Summary. When stratified by weight loss (inclusive of all groups), improvements in IWQOL-Lite and SF-36 were greater with greater weight reductions [48].

\section{CONCLUSION}

The authors identified five major points regarding PHN/TPM treatment. (1) Weight loss exceeds FDA efficacy benchmarks and appears to continue or be maintained for at least 2 years with continued use of the drug. (2) The most common adverse effects include paresthesia, dry mouth, and constipation. Among psychiatric side effects, anxiety symptoms seem to be most common. (3) Laboratory abnormalities can include reductions in bicarbonate and in some cases hypokalemia. (4) PHN/TPM should be avoided in women desiring pregnancy or becoming pregnant due to potential teratogenic effects associated with topiramate (particularly oral cleft defects). (5) Weight loss induced by PHN/TPM 7.5/46 mg and 15/92 mg improved both weight-specific and physical quality of life concerns, but did not improve general mental/ psychosocial concerns.

\section{ACKNOWLEDGMENTS}

Dr. Steffen is the guarantor for this article, and takes responsibility for the integrity of the work as a whole.

Conflict of Interest. Neither author received any funding/sponsorship for preparing this manuscript. Dr. Kolotkin has received financial compensation for previous consulting work for Vivus and Orexigen. 
Open Access. This article is distributed under the terms of the Creative Commons Attribution Noncommercial License which permits the use, distribution, and reproduction in any medium, provided the original author(s) and source are credited.

\section{REFERENCES}

1. Flegal KM, Carroll MD, Ogden CL, Johnson CL. Prevalence and trends in obesity among US adults, 1999-2000. JAMA. 2002;288:1723-7.

2. Kolotkin RL, Meter K, Williams GR. Quality of life and obesity. Obes Rev. 2001;2:219-29.

3. Kushner RF, Foster G. Obesity and quality of life. Nutrition. 2000;16:947-52.

4. Fontaine KR, Barofsky I. Obesity and health-related quality of life. 2001;2:173-82.

5. Flegal KM, Carroll MD, Kit BK, Ogden CL. Prevalence of obesity and trends in the distribution of body mass index among US adults, 1999-2010. JAMA. 2012;307:491-7. Epub 2012 Jan 17.

6. Finkelstein EA, Trogdon JG, Cohen JW, Dietz W. Annual medical spending attributable to obesity: payer- and service-specific estimates. Health Aff (Millwood). 2009;28:w822-31.

7. Centers for Disease Control. Leading causes of death. Available at: http://www.cdc.gov/nchs/ fastats/lcod.htm/. Accessed Jul 292012.

8. The Obesity Society. Statement of the Obesity Society regarding FDA review and approval of promising new obesity drugs. Available at: http:// www.obesity.org/images/pdf/statement_fda_ review_of_new_drugs_rev_06-8-11.pdf. Accessed Jul 29 2012.

9. National Weight Control Registry. Research Findings. Available at: http://www.nwcr.ws/default. htm. Accessed Jul 292012.

10. NHLBI: The practical guide: Identification, evaluation, and treatment of overweight and obesity in adults, 2000. Available at: http://www. nhlbi.nih.gov/guidelines/obesity/prctgd_b.pdf. Accessed Aug 12012.

11. Lyznicki JM, Young DC, Riggs JA, Davis RM. Obesity: assessment and management in primary care. Am Fam Physician. 2001;63:2185-96.
12. Mechanick JI, Kushner RF, Sugerman HJ, et al. American Association of Clinical Endocrinologists, The Obesity Society, and American Society for Metabolic and Bariatric Surgery Medical Guidelines for Clinical Practice for the Perioperative Nutritional, Metabolic, and Nonsurgical Support of the Bariatric Surgery Patient. Endocr Pract. 2008;14(Suppl. 1):1-83.

13. US Department of Health and Human Services Food and Drug Administration Center for Drug Evaluation and Research (CDER). Guidance for industry: Developing products for weight management. Available at: http://www.fda.gov/ downloads/Drugs/.../Guidances/ucm071612.pdf. Accessed Jul 292012.

14. Ioannides-Demos LL, Piccenna L, McNeil JJ. Pharmacotherapies for obesity: past, current, and future therapies. J Obes. 2011;179674. Epub 2010 Dec 12 .

15. Kernan WN, Viscoli CM, Brass LM, et al. Phenylpropanolamine and the risk of hemorrhagic stroke. N Engl J Med. 2000;343:1826-32.

16. Connolly HM, Crary JL, McGoon MD, et al. Valvular heart disease associated with fenfluraminephentermine. N Engl J Med. 1997;337:581-8.

17. Graham DJ, Green L. Further cases of valvular heart disease associated with fenfluramine-phentermine. N Engl J Med. 1997;337:635.

18. James WP, Caterson ID, Coutinho W, et al.; the SCOUT Investigators. Effect of sibutramine on cardiovascular outcomes in overweight and obese subjects. N Engl J Med. 2010;363:905-17.

19. Anderson JW. Orlistat for the management of overweight individuals and obesity: A review of potential for the 60-mg, over-the-counter dosage. Expert Opin Pharmacother. 2007;8:1733-42.

20. Li Z, Maglione M, Tu W. Meta-analysis: Pharmacologic treatment of obesity. Ann Intern Med. 2005;142:532-46.

21. US Food and Drug Administration. Food and Drug Administration News Release: FDA approves Belviq to treat some overweight or obese adults. Available at: http://www.fda.gov/NewsEvents/Newsroom/ PressAnnouncements/ucm309993.htm. Accessed Jul 292012.

22. US Food and Drug Administration. VI-0521 $\left(\right.$ Qnexa $\left.^{\circledR}\right)$ Advisory Committee Briefing Document. Vivus, Inc. Available at: www.fda.gov/downloads/ AdvisoryCommittees/.../Drugs/.../UCM292317.pdf. Accessed Jul 292012. 
23. Topiramate. In: Lexi-Drugs Online [database on the Internet]. Ohio: Lexi-Comp, Inc.; 2007 [cited July 2012]. Available at: http://online.lexi.com. Accessed July 29, 2012.

24. Arroyo S, Dodson WE, Privitera MD, et al.; EPMN106/INT-28 Investigators. Randomized dosecontrolled study of topiramate as first-line therapy in epilepsy. Acta Neurol Scan. 2005;112:214-22.

25. Vivus, Inc. Qsymia ${ }^{\circledR}$ Package Insert. Available at: http://vivus.com/docs/QsymiaPI.pdf. Accessed Jul 292012.

26. Primack C, Scinta W. Qnexa (phentermine/ topiramate): Past, present, future. Bariatric Times. 2011;9:10-1.

27. Malessa R, Gendolla A, Steinberg B, et al.; TOPMATMIG-3004 Investigators. Prevention of episodic migraine with topiramate: a prospective 24-week, open-label, flexible-dose clinical trial with optional 24 weeks follow-up in a community setting. Curr Med Res Opin. 2010;26:1119-29.

28. Silberstein SD, Lipton RB, Dodick DW, et al.; Topimarate Chronic Migraine Study Group. Efficacy and safety of topiramate for the treatment of chronic migraine: a randomized, double-blind, placebo-controlled trial. Headache. 2007;47:170-80.

29. Nickel C, Tritt K, Muehlbacher M, et al. Topiramate treatment in bulimia nervosa patients: a randomized, double-blind, placebo-controlled trial. Int J Eat Disord. 2005;38:295-300.

30. Hoopes SP, Reimherr FW, Hedges DW, et al. Treatment of bulimia nervosa with topiramate in a randomized, double-blind, placebo-controlled trial, part 1: improvement in binge and purge measures. J Clin Psychiatry. 2003;64:1335-41.

31. Shapira NA, Goldsmith TD, McElroy SL. Treatment of binge-eating disorder with topiramate: a clinical case series. J Clin Psychiatry. 2000;61:368-72.

32. McElroy SL, Hudson JI, Capece JA, et al. Topiramate for the treatment of binge eating disorder associated with obesity: A placebo-controlled study. Biol Psychiatry. 2007;61:1039-48.

33. Hahn MK, Remington G, Bois D, Cohn T. Topiramate augmentation in clozapine-treated patients with schizophrenia: clinical and metabolic effects. J Clin Psychopharmacol. 2010;30:706-10.

34. Narula PK, Rehan HS, Unni KE, Gupta N. Topiramate for prevention of olanzapine associated weight gain and metabolic dysfunction in schizophrenia: a double-blind, placebo-controlled trial. Schizophr Res. 2010;118:218-23.

35. Kramer CK, Leitao CB, Pinto LC, Canani LH, Azevedo MJ, Gross JL. Efficacy and safety of topiramate on weight loss: a meta-analysis of randomized controlled trials. Obes Rev. 2011;12:e338-47.

36. Yaman M, Ucok K, Demirbas $H$, et al. Effects of topiramate use on body composition and resting metabolic rate in migraine patients. Neurol Sci, 2012; Mar 6. [Epub ahead of print].

37. Gadde KM, Allison DB, Ryan DH et al. Effects of a low-dose, controlled-release, phentermine plus topiramate combination on weight and associated comorbidities in overweight and obese adults (CONQUER): a randomised, placebo-controlled, phase 3 trial. Lancet. 2011;377:1341-52.

38. Dickerson LM, Carek PJ. Pharmacotherapy for the obese patient. Prim Care. 2009;36:407-15.

39. Allison DB, Gadde KM, Garvey WT, et al. Controlled-release phentermine/topiramate in severely obese adults: a randomized controlled trial (EQUIP). Obesity (Silver Spring). 2012;20:330-42.

40. Garvey WT, Ryan DH, Look M. Two-year sustained weight loss and metabolic benefits with controlledrelease phentermine/topiramate in obese and overweight adults (SEQUEL): a randomized, placebo-controlled, phase 3 extension study. Am J Clin Nutr. 2012;95:297-308.

41. Brownell KD. The LEARN Program for Weight Management. 10th edition. Dallas: American Health Publishing Company; 2004.

42. US Food and Drug Administration. Food and Drug Administration Briefing Document NDA 22529: Lorcaserin Hydrochloride. Available at: www.fda. gov/downloads/AdvisoryCommittees/.../Drugs/.../ UCM303198.pdf. Accessed Jul 292012.

43. Orexigen Therapeutics, Contrave. Available at: http://www.orexigen.com/candidates/candidates_ contrave.php. Accessed Jul 292012.

44. Kroenke K, Spitzer RL. The PHQ-9: A new depression and diagnostic severity measure. Psychiatric Annals. 2002;32:509-21.

45. Posner K, Brent D, Lucas C, et al. Columbia-Suicide Severity Rating Scale (C-SSRS). Version 1-14-09. Available at: http://www.maps.org/mdma/mt1 docs/c-ssrs1-14-09-baseline.pdf. Accessed Jul 29 2012. 
46. Ware J, Snow K, Kosinski M, Gandek B. SF-36 Health Survey: Manual and Interpretation Guide. Boston: The Health Institute, New England Medical Center; 1993.

47. Kolotkin RL, Crosby RD, Kosloski KD, Williams GR. Development of a brief measure to assess quality of life in obesity. Obes Res. 2001;9:102-11.
48. Kolotkin RL, Gadde K, Peterson C. Quality of life improvements and related to the magnitude of weight loss with controlled-release phentermine/ topiramate (PHN/TPM ER) in obese patients. Obesity Facts. 2012;5(Suppl.1):A208. 